\title{
Pengaruh sadar wisata, kemenarikan fasilitas dan jarak terhadap minat berkunjung kembali pada objek wisata Merangin Garden di Kabupaten Merangin
}

\author{
Muttakin Ab; *Zulfanetti; Jaya Kusuma Edy \\ Prodi. Ekonomi Pembangunan, Fakultas Ekonomi dan Bisnis, Universitas Jambi \\ E-mail korespondensi: zulfanetti@yahoo.com
}

\begin{abstract}
Tourism is the fastest growing foreign exchange earning subsector and the increase is almost happening in all regions, Merangin regency has a great potential in tourism. The purpose of this study is to analyze the characteristics of visitors or tourists, identify factors that affect the interest of tourists to visit again, and how important is the participation of the community around the tourism object. The data used in this study are primary data obtained from questionnaires and direct interviews with a sample of 35 people. The sampling method used is convenient random sampling. The data analysis tool used is quantitative with multiple liner analysis used Eviews 9 software. Merangin garden tourist characteristics in Merangin district are known that the average age of the visitors is 39. The sex of visitors or tourists is male, education is high school / equivalent, the number of dependents of visitors is 4 people where visitors live are Merangin and surrounding communities. The distance between visitors to the Merangin Garden attraction is $30 \mathrm{~km}$ on average.
\end{abstract}

Keywords: Returning Interests, Tourism Awareness, Facility and Distance Attractiveness, Merangin Garden.

\begin{abstract}
Abstrak
Pariwisata merupakan subsektor penghasil devisa dengan perkembangan tercepat serta peningkatannya hampir terjadi disemua daerah, kabupaten merangin memiliki potensi yang besar di bidang pariwisata. Tujuan penelitian ini adalah untuk menganalisis karakteristik para pengunjung atau wisatawan, mengidentifikasi faktor yang mempengaruhi minat berkunjung kembali wisatawan, serta seberapa penting partisipasi masyarakat sekitar objek wisata merangin garden. Data yang digunakan dalam penelitian ini adalah data primer yang diperoleh dari kuisioner dan wawancara langsung dengan jumlah sampel 35 orang. Metode penarikan sampel yang digunakan convenient random sampling. Alat analisis data yang digunakan yaitu kuantitatif dengan analisis liner berganda digunakan sofware Eviews 9. Karakteristik wisatawan merangin garden di kabupaten merangin diketahui bahwa rata-rata umur para pegunjung adalah 39. Jenis kelamin pengunjung atau wisatawan adalah laki-laki, pendidikan adalah SMA/sederajat, jumlah tanggungan pengunjung adalah 4 orang dengan tempat tinggal pengunjung adalah masyarakat merangin dan sekitar. Jarak para pengunjung objek wisata merangin garden rata-rata $30 \mathrm{~km}$.
\end{abstract}

Kata Kunci: Minat Berkunjung Kembali, Sadar Wisata, Kemenarikan Fasilitas Dan Jarak, Merangin Garden. 


\section{PENDAHULUAN}

Pariwisata merupakan salah satu pemanfaatan sumber daya alam yang dapat bernilai ekonomi tinggi bagi suatu daerah yang mengelola sumber daya alam menjadi suatu tempat wisata yang dapat menarik pengunjung baik dari dalam maupun dari luar negeri, disamping bernilai ekonomi yang tinggi, pariwisata dapat menumbuhkan dan meningkatkan rasa bangga terhadap bangsa sehingga akan tumbuh masyarakat yang lebih peduli terhadap suatu bangsa. Pariwisata adalah hal yang diminati oleh setiap individu, karena dapat menghilangkan kejenuhan, berkembangnya kreativitas dan mampu menunjang produktivitas suatu individu (Warren, 2005).

Sadar Wisata adalah pengertian yang mendalam pada orang, seseorang atau sekelompok orang yang terwujud dalam pemikiran, sikap dan tingkah laku yang mendukung pengembangan pariwisata. Program peningkatan Sadar Wisata dilakukan dengan pembinaan dan latihan yang menyangkut masalah Sadar Wisata dan penguatan citra (Ahmadi, 2019).

Kemenarikan fasilitas merupakan faktor penting agar pengunjung atau wisatawan berniat untuk mengunjungi suatu objek wisata, fasilitas yang menarik dan nyaman membuat pengunjung betah untuk berlama-lama mengunjungi suatu objek wisata. Baik itu fasilitas fisik maupun fasilitas non fisik dan pada akhirnya objek wisata ini akan semakin banyak pengunjunnya (Joni, 2019)

Faktor ketiga Minat Berkunjung Kembali ditentukan oleh faktor Jarak (Distance), Jarak adalah angka yang menunjukkan seberapa jauh Jarak yang telah ditempuh wisatawan untuk sampai di obyek wisata yang ingin dikunjungi. Dalam memperkirakan nilai tempat wisata tersebut akan menyangkut waktu dan biaya yang dikorbankan oleh para wisatawan dalam menuju dan meninggalkan tempat wisata tersebut. Semakin jauh Jarak wisatawan ke tempat wisata tersebut, akan semakin rendah permintaannya terhadap tempat wisata tersebut. Para wisatawan yang lebih dekat dengan lokasi wisata tentu akan lebih sering berkunjung ke tempat wisata tersebut dengan adanya biaya yang lebih murah yang tercermin pada biaya perjalanan yang dikeluarkan. Dalam hal ini dapat dikatakan bahwa wisatawan mendapatkan surplus konsumen. Surplus konsumen merupakan kelebihan kesediaan membayar atas harga yang telah ditentukan. Oleh karena itu surplus konsumen yang dimiliki oleh wisatawan yang jauh tempat tinggalnya dari tempat wisata akan lebih rendah dari pada mereka yang lebih dekat tempat tinggalnya dari tempat wisata tersebut (Suparmoko, 2002).

\section{METODE}

\section{Metode penelitian}

Metode yang digunakan dalam penelitian ini adalah metode survei, dimana peneliti dalam memperoleh informasi dan data-data berasal dari responden yang telah dijadikan sampel menggunakan daftar pertanyaan-pertanyaan (kuisioner) yang terpola dan terstruktur serta sesuai dengan kebutuhan. Metode survei adalah suatu penelitian yang dilakukan dimana didalam melakukan penelitian data yang dikumpulkan untuk dianalisis dalam jangka waktu tertentu secara bersamaan dalam rangka membuktikan hipotesis atau pemecahan masalah (amir, junaidi, yulmardi, 2009). Survei diartikan sebagai pendeskripsian suatu kegiatan yang berhubungan dengan suatu metode pengumpulan data untuk mengumpulkan data mengenai perilaku pendududk, sikap, kepercayaan, karakteristik, pengetahuan atau ekpektasi responden terhadap objek wisata merangin garden di Kabupaten Merangin( lembaga demografi FEUI, 2010). 


\section{Jenis data}

Data primer merupakan data yang dikumpulkan, diolah dan disajikan oleh pihak pertama dan biasanya sudah dipublikasikan oleh pihak pertama. Data primer terdiri dari: data kondisi sosial ekonomi responden yaitu jenis kelamin, umur, pendidikan, pekerjaan dan jumlah anak.

\section{Sumber data}

Dalam penelitian ini data primer diperoleh langsung dari objek penelitian yang dikumpulkan melalui wawancara dengan responden dan mengunakan alat yaitu daftar pertanyaan (kuisioner) dan obesrvasi yaitu yang berhubungan dengan wisatawan objek wisata merangin garden. Sebagaimana dalam penjelasan sebelumnya, sumber data primer adalah data yang dikumpulkan secara langsung oleh peneliti. Metode atau pendekatan yang dapat dilakukan dalam proses pengumpulan data yang bersifat primer ini dapat menggunakan angket atau kuesioner, wawancara, pengamatan, tes, dokumentasi dan sebagainya.

\section{Metode penarikan sampel Populasi}

Populasi adalah generalisasi yang terdiri atas: objek atau subjek yang mempunyai kualitas dan karakteristik tertentu. Dalam penelitian ini peneliti mengunakan populasi responden yang berkunjung ke objek wisata merangin garden.

\section{Sampel}

Sampel adalah bagian dari jumlah dan karakteristik yang dimiliki oleh populasi tersebut. penelitian ini mengunakan data jenis cross section dan teknik pengambilan sampel secara purposif (sengaja) dengan melihat keadaan jumlah responden di objek wisata merangin garden.

\section{Metode analisis data}

Metode analisis data yang digunakan dalam penelitian ini adalah persamaan regresi linier berganda yaitu persamaan regresi yang melibatkan 2 (dua) variabel atau lebih. Regresi linier berganda digunakan untuk mengetahui besarnya pengaruh perubahan dari sesuatu variabel independen terhadap variabel dependen. varibel sadar wisata, kemenarikan fasilitas dan jarak yang mempengaruhi minat berkunjung kembali pada objek wisata merangin garden dengan mengunakan metode purposif random sampling.

\section{Metode deskriptif}

Metode deskriptif adalah suatu metode dalam meneliti status kelompok manusia, suatu objek, suatu sistem pemikiran, ataupun suatu kelas peristiwa pada masa sekarang. Dalam penelitian ini metode deskriftif digunakan untuk mengambarkan jenis kelamin, umur, pendidikan, pekerjaan dan jumlah anak serta menentukan rata-rata, angka maksimum dan minimum variabel sadar wisata, kemenarikan fasilitas dan jarak di objek wisata merangin garden (Ghozali, 2011).

Metode kuantitatif dalam penelitian ini digunakan untuk menjelaskan pengaruh sadar wisata, kemenarikan fasilitas, dan jarak terhadap minat berkunjung kembali mengunakan analisis regresi berganda dengan metode ordinary least square (OLS) untuk menghitung rata-rata pengaruh sadar wisata, kemenarikan fasilitas dan jarak terhadap minat berkunjung kembali di objek wisata merangin garden (Hang, 2006). 


\section{Uji asumsi klasik}

Pengujian ini dilakukan untuk melihat model kemungkinan adanya gejala heterokedastisitas, yaitu menunjukkan adanya varian yang tidak konstan dari variabel residul, multikolinearitas yang merupakan keadaan diamana satu atau lebih variabel bebas dapat dikatakan sebagai kombinasi dari variabel bebas lainnya, dan normalitas yaitu menunjukkan keadaan dimana terjadi normal atau tidak suatu variabel di dalam regresi linear (Gujarati, 2016).

\section{Uji multikolinearitas}

Uji multikolinearitas digunakan sebagai upaya untuk menentukan ada dan tidaknya korelasi yang sempurna atau mendekat hubungan yang sempurna. Menurut Hasan seorang ahli ekonomi dari mesir berpendapat non-multikolinearitas adalah hubungan anatara variabel bebas yang satu dengan variabel yang lain dengan model regresi tidak terjadi hubungan yang sempurna. Kekuatan hubungan korelasi diukur berdasarkan skala $\mathrm{r}$ adalah o sampai dengan 1 (berlaku untuk $\mathrm{r}$ positif maupun negatif).

\section{Uji heteroskodastisitas}

Menurut Sugiyono (2002) Heteroskodastisitas berarti variasi (varians) variabel tidak sama untuk semua pengamatan. Pada heroskodastisitas, kesalahan yang terjadi random (acak) tetapi memperhatikan hubungan yang sistematis sesuai dengan besarnya satu atau lebih variabel bebas.

\section{Uji normalitas}

Uji normalitas bertujuan untuk menguji apakah dalam model regresi variabel dependen dan variabel independen mempunyai distribusi normal atau tidak. Model regresi yang baik adalah yang mempunyai distribusi data normal atau mendekati normal. Dalam uji normalitas untuk menentukan normal atau tidaknya dapat dilihat dari signifikan menunjukkan $\geq 0.05$ maka data tersebut berdistribusi normal, sebaliknya jika angka signifikan menunjukkan $<0,05$ maka data tersebut tidak normal (Sugiyono, 2002).

\section{Pengujian hipotesis Koefisien determinasi}

Koefisien determinasi $\left(R^{2}\right)$ pada intinya mengukur seberapa jauh kemampuan modal dalam menerangkan variabel independe. Nilai koefisien determinasi adalah antara 0-1. Nilai $R^{2}$ yang kecil berarti kemampuan variabel-variabel independen dalam menjelaskan variabel dependen sangat luas. Nilai yang mendekati satu berarti variabelvariabel independen memberikan hampir semua informasi yang dibutuhkan untuk memprediksi variabel-variabel dependen (Sugiyono, 2002). koefisien determinasi adalah angka yang menyatakan atau digunakan untuk mengetahui atau sumbangan yang diberikan oleh sebuah variabel X (bebas) terhadap variabel Y (terikat).

\section{Uji simultan (Uji F)}

Uji f pada dasarnya dimaksudkan untuk membuktikan secara statistik bahwa satu persatu variabel bebas berpengaruh signifikan terhadap variabel terikat. Dalam uji t, jika nilai probabilitas lebih kecil dari $\alpha 10 \%$ maka setiap variabel bebas itu satu persatu memmiliki pengaruh yang signifikan secara statistik terhadap variabel terikat (Sugiyono, 2002). 


\section{Uji parsial (Uji t)}

Uji t dimaksudkan dimaksudkan untuk membuktikan secara statistik bahwa satu persatu variabel bebas berpengaruh signifikan terhadap variabel terikat. Dalam uji t, jika nilai probabilitas lebih kecil dari pada $\alpha 10 \%$, maka setiap variabel bebas itu satu persatu memiliki pengaruh yang signifikan secara statistik terhadap variabel terikat (Sugiyono, 2002).

\section{HASIL DAN PEMBAHASAN}

\section{Karakteristik wisatawan merangin garden} Jenis kelamin

Karakteristik wisatawan merangin garden menurut jenis kelamin mencerminkan berapa banyak jenis kelamin laki-laki dan perempuan dalam mengunjungi objek wisata merangin garden di tahun 2019. Adapun distribusi responden berdasarkan jenis kelamin wisatawan di objek wisata merangin garden kelurahan pematang kandis tahun 2019 dapat dilihat pada tabel berikut :

Tabel 1. Distribusi frekuensi responden berdasarkan jenis kelamin wisatawan di objek wisata merangin garden tahun 2019

\begin{tabular}{ccc}
\hline Jenis kelamin & Frekuensi (n) & Persentase (\%) \\
\hline Laki-Laki & 26 & 74,28 \\
Perempuan & 9 & 25,72 \\
Jumlah & 35 & 100 \\
\hline
\end{tabular}

\section{Sumber: Data diolah,2019}

\section{Umur}

Karakteristik wisatawan merangin garden menurut kelompok umur mencerminkan angka beban dibandingkan dengan jumlah penduduk produktif (20-60 tahun) dan jumlah yang tidak produktif dibawah 20 tahun dan 60 tahun keatas (Yoeti 2016). Adapun distribusi responden berdasarkan umur wisatawan di objek wisata merangin garden kelurahan pematang kandis tahun 2019 dapat dilihat pada tabel berikut :

Tabel 2. Distribusi frekuensi responden berdasarkan umur wisatawan di objek wisata Merangin Garden Tahun 2019

\begin{tabular}{|c|c|c|}
\hline Umur (Tahun) & Frekuensi (n) & Persentase (\%) \\
\hline $18-24$ & 3 & 8,5 \\
\hline $25-29$ & 7 & 20 \\
\hline $30-34$ & 6 & 17,1 \\
\hline $35-39$ & 4 & 11,4 \\
\hline $40-49$ & 9 & 25,7 \\
\hline $50-54$ & 3 & 8,5 \\
\hline $55-59$ & 1 & 2,8 \\
\hline$>60$ & 2 & 5,7 \\
\hline Jumlah & 35 & 100 \\
\hline
\end{tabular}

Sumber : Data diolah,2019 


\section{Pendidikan}

Tingkat pendidikan seseorang menunjukan pengetahuan yang dimiliki oleh wisatawan. Tingkat pendidikan wisatawan yang relatif tinggi akan mempengaruhi cara berpikir dan pengambilan keputusan dalam melaksanakan aktivitas.

Tabel 3. Distribusi frekuensi responden berdasarkan pendidikan wisatawan di objek wisata Merangin Garden Tahun 2019

\begin{tabular}{|c|c|c|}
\hline Pendidikan & Frekuensi (n) & Persentase (\%) \\
\hline Tidak Tamat Sekolah & 2 & 5,7 \\
\hline $\mathrm{SD}$ & 4 & 11,42 \\
\hline SMP & 10 & 28,57 \\
\hline SMA & 13 & 37,14 \\
\hline Perguruan Tinggi & 6 & 17,14 \\
\hline Jumlah & 35 & 100 \\
\hline Rata-rata & & \\
\hline
\end{tabular}

Sumber : Data diolah, 2019

\section{Pekerjaan}

Karakteristik wisatawan merangin garden menurut pekerjaan mencerminkan bagaimana kebanyakan wisatawan, Pekerjaan yang relatif mudah dan ada waktu luang membuat wisatawan ingin mengunjungi objek wisata merangin garden kembali. Adapun distribusi responden berdasarkan jenis kelamin wisatawan di objek wisata merangin garden kelurahan pematang kandis tahun 2019 dapat dilihat pada tabel berikut:

Tabel 4. Distribusi frekuensi responden berdasarkan pekerjaan wisatawan di objek wisata Merangin Garden Tahun 2019

\begin{tabular}{ccc}
\hline Pekerjaan & Frekuensi (n) & Persentase (\%) \\
\hline Mahasiswa & 4 & 11,42 \\
Swasta & 21 & 60 \\
LSM & 1 & 2,86 \\
TU SD & 1 & 2,86 \\
PNS & 7 & 20 \\
Jumlah & 35 & 100 \\
\hline Rata-Rata & Swasta \\
\hline
\end{tabular}

Sumbe : Data diolah, 2019

\section{Jumlah tanggunan (Anak)}

Jumlah tanggungan keluarga adalah banyaknya orang yang ditanggung atau dibiayai oleh kepala keluarga. Jumlah tanggungan akan mempengaruhi kunjungan kembali karena banyak keluarga yang ditanggung maka akan mempengaruhi hasrat atau kemampuan seseorang untuk berwisata. Karena kebanyakan wisatawan yang berkunjung ke objek wisata merangin garden ini mengajak keluarga, teman dan sahabat kantornya. 
Tabel 5. Distribusi frekuensi responden berdasarkan kelompok jumlah tanggungan wisatawan di Merangin Garden Tahun 2019

\begin{tabular}{ccc}
\hline $\begin{array}{c}\text { Jumlah Tanggungan } \\
\text { (Jiwa) }\end{array}$ & Frekuensi (n) & Persentase (\%) \\
\hline $0-1$ & 4 & 11,42 \\
$2-4$ & 26 & 74,28 \\
$>5$ & 5 & 14,28 \\
Jumlah & 35 & 100 \\
\hline Rata-Rata & $\mathbf{3}$ & \\
\hline
\end{tabular}

Sumber: Data diolah, 2019

Analisis besaran minat berkunjung kembali wisatawan dan variabel penelitian di objek wisata Merangin Garden

Sesuai dengan tujuan penelitian ini, yakni untuk menganalisis besaran Minat Berkunjung Kembali Wisatawan dan variabel penellitian Pada Objek Wisata Merangin Garden. Dapat dilihat sebagai berikut :

Tabel 6. Besaran minat berkunjung kembali wisatawan dan variabel penelitian di objek wisata Merangin Garden

\begin{tabular}{lccc}
\hline \multicolumn{1}{c}{ Variabel } & Rata-Rata & Maksimum & Minimum \\
\hline Minat Berkunjung & 3,29714 & 24 & 8 \\
Kembali (Y) & & & \\
Sadar Wisata (X1) & 3,34285 & 25 & 5 \\
Kemenarikan & 2,87429 & 22 & 5 \\
Fasilitas (X2) & & & 1 \\
\hline Jarak (X3) & 3,08571 & 5 & \\
\hline
\end{tabular}

Sumber: Data diolah, 2019

Analisis pengaruh sadar wisata, kemenarikan fasilitas dan jarak terhadap minat berkunjung kembali di objek wisata Merangin Garden

Analisis regresi berganda

Model Regresi berganda adalah pengaruh sadar wisata, kemenarikan fasilitas dan jarak terhadap minat berkunjung kembali di objek wisata merangin garden. Berikut hasil dari metode analisa dan perhitungan yang dilakukan melalui program Eviews9 dengan taraf signifikan $\alpha=1 \%, \alpha=5 \%, \alpha=10 \%$, maka diperoleh persamaan regresi sebagai berikut :

$$
\mathrm{MBK}=4.22130+0.3475 \mathrm{MbSD}+0.3330 \mathrm{MbKF}+-0.2519 \mathrm{MbJR}
$$
$(0.793)$
$(0.1493)$
$(0.1475)$
$(0.1212)$

Nilai kostanta sebesar 4.22130 memberikan arti bahwa jika sadar wisata (SW), kemenarikan fasilitas (KF) dan jarak (JK) diasumsikan tetap atau konstan, maka minat berkunjung kembali akan dikunjungi oleh wisatatawan sebanyak 4.22130 kali. Sadar wisata (SW) berpengaruh terhadap minat berkunjung kembali dan mempunyai koefisien regresi sebesar 0.3475 bahwa setiap penambahan $1 \%$ sadar wisata masyarakat terjadi kenaikan jumlah kunjungan kembali wisatawan sebesar 0.3475 dengan asumsi variabel lainnya tetap atau kostan (ceteris paribus). Kemenarikan fasilitas (KF) berpengaruh terhadap minat berkunjung kembali dan mempunyai koefisien regresi sebesar 0.3330 bahwa setiap penambahan $1 \%$ fasilitas terjadi kenaikan jumlah kunjungan kembali wisatawan sebesar 0.3330 dengan asumsi variabel lainnya tetap atau konstan (ceteris 
paribus). Jarak (JK) berpengaruh terhadap minat berkunjung kembali dan mempunyai koefisien regeresi sebesar -0.2519 bahwa semakin dekat jarak membuat wisatawan semakin kurang untuk minat berkunjung kembali ke objek wisata merangin garden.

\section{Uji asumsi klasik \\ Multikolinearitas}

Multikolinearitas sebagai suatu keadaan dimana terjadi korelasi linear yang "Prefect" atau exact sebagian atau semua variabel bebas alam model regresi sehingga menyulitkan untuk mengidentifikasi variabel bebas dan variabel terikatnya yaitu sadar wisata, kemenarikan fasilitas, dan jarak terhadap minat berkunjung kembali. Setelah hasil estiminasi maka dapat dilihat dari varians inflation faktor (VIF) sebagai berikut:

Tabel 7. Hasil variance inflation factor

\begin{tabular}{crrc}
\hline Variabel & $\begin{array}{c}\text { Coeficient } \\
\text { variance }\end{array}$ & $\begin{array}{c}\text { Uncentered } \\
\text { VIF }\end{array}$ & $\begin{array}{c}\text { Centered } \\
\text { VIF }\end{array}$ \\
\hline \hline $\mathrm{X} 1$ & 1.000000 & -0.254815 & 0.057813 \\
$\mathrm{X} 2$ & -0.254815 & 1.000000 & 0.086367 \\
$\mathrm{X} 3$ & 0.057813 & 0.086367 & 1.000000 \\
\hline
\end{tabular}

Sumber: Data diolah, 2019

\section{Heterokedastisitas}

Hasil regresi heterokedastisitas untuk menguji R-squared setiap variabel independen (Sadar Wisata, Kemenarikan Fasilitas, Dan Jarak) yang mempengaruhi variabel dependen (minat berkunjung kembali) mempunyai varians yang sama. Jika terjadi heterokedastisitas maka penaksir OLS tetap tak bisa dan konsisten, tetapi penaksir tidak lagi efisien baik dalam sampel kecil maupun besar. Berikut ini model heterokedastisitas dapat dilihat tabel:

Tabel 8. Hasil regresi heterokedastisitas

Heteroskedasticity Test: Breusch-Pagan-Godfrey

\begin{tabular}{clll}
\hline \hline F-statistic & 0.467479 & Prob. F(3,30) & 0.7072 \\
Obs*R-squared & 1.518444 & Prob. Chi-Square(3) & 0.6780 \\
Scaled explained SS & 1.271734 & Prob. Chi-Square(3) & 0.7359 \\
\hline
\end{tabular}

Sumber: Data Diolah, 2019

\section{Normalitas}

Uji yang dilakukan untuk mengevaluasi apakah nilai variabel pengganggu dari model yang di bentuk sudah berdistribusi normal atau tidak. Konsep uji normalitas menggunakan pendekatan jourque-berra test. Pedoman dari J-B test adalah apabila nilai probabilitas J-B hitung $<$ nilai probabilitas $\alpha(0,05)$, maka hipotesis menyatakan bahwa variabel pengganggu adalah berdistribusi normal ditolak. Apabila nilai probabilitas J-B hitung $>$ nilai probabilitas $\alpha(0,05)$, maka hipotesis yang menyatakan bahwa variabel pengganggu adalah berdistribusi normal diterima. Berikut ini grafik uji normalitas : 


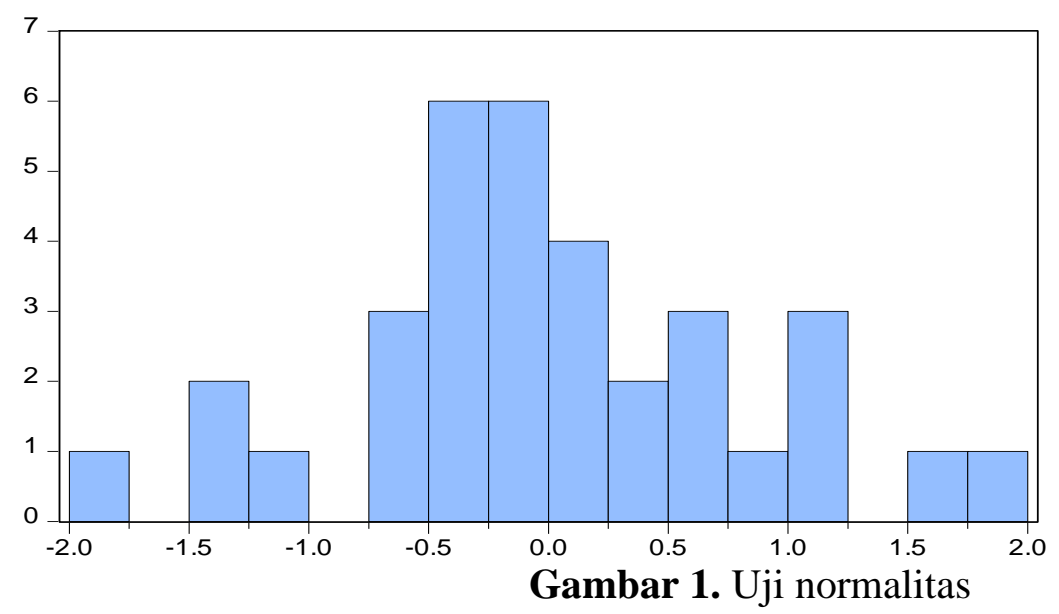

\begin{tabular}{|lr}
\hline \multicolumn{2}{l}{ Series: Residuals } \\
Sample 1 34 \\
Observations 34 \\
Mean & $1.40 \mathrm{e}-15$ \\
Median & -0.100682 \\
Maximum & 1.771906 \\
Minimum & -1.972594 \\
Std. Dev. & 0.819358 \\
Skewness & -0.038254 \\
Kurtosis & 3.151508 \\
& \\
Jarque-Bera & 0.040811 \\
Probability & 0.979801 \\
\hline
\end{tabular}

\section{Pengujian hipotesis \\ Uji F statistik}

Uji f-statistik dilakukan dengan tujuan untuk mengetahui apakah secara bersamasama variabel: independen berpengaruh signifikan terhadap variabel dependen yaitu dengan melihat signifikan $\alpha 5 \%$. Apabila tingkat signifikan lebih kecil dari $\alpha 5 \%$ maka Ho ditolak Ha diterima artinya bersama-sama variabel bebas tersebut berpengaruh signifikan terhadap variabel terikat, begitu juga sebaliknya apabila taraf signifikan lebih besar dari $\alpha$ 5\% maka Ho diterima Ha ditolak artinya secara bersama-sama variabel bebas tidak berpengaruh signifikan terhadap variabel terikat. Berikut hasil F statistik.

Tabel 9. Hasil regresi linear berganda menguji $F$ statistik

\begin{tabular}{lrll} 
R-squared & 0.379508 & Mean dependent var & 3.252941 \\
Adjusted R-squared & 0.317459 & S.D. dependent var & 1.040173 \\
S.E. of regression & 0.859350 & Akaike info criterion & 2.644850 \\
Sum squared resid & 22.15448 & Schwarz criterion & 2.824422 \\
Log likelihood & -40.96245 & Hannan-Quinn criter. & 2.706089 \\
F-statistic & 6.116248 & Durbin-Watson stat & 0.628319 \\
Prob(F-statistic) & 0.002252 & & \\
\hline
\end{tabular}

Sumber: Data diolah, 2019

\section{Uji t statistik}

Faktor-faktor yang mempengaruh terhadap minat berkunjung kembali adalah sadar wisata, kemenarikan fasilitas dan jarak. Perhitungan dapat digunakan menerima atau menolak hipotesis yang dirumuskan, yaitu dengan melihat taraf signifikan $\alpha=$ $1 \%, 5 \%$ dan $10 \%$. Apabila probabilitas lebih kecil dari taraf signifikan yang telah ditetapkan maka Ho ditolak Ha diterima artinya parsial variabel bebas berpengaruh secara signifikan terhadap variabel terikat Begitu juga sebaliknya, apabila probabilitas lebih besar dari pada tingkat signifikan yang ditetapkan maka Ho diterima Ha ditolak artinya secara parsial variabel bebas tidak berpengaruh secara signifikan terhadap variabel terikat. Hasil regresi linear berganda untuk menguji t statistik dapat dilihat dari tabel berikut. 
Tabel 10. Hasil regresi linear berganda menguji t statistik

\begin{tabular}{crrrr}
\hline \hline Variable & Coefficient & Std. Error & t-Statistic & Prob. \\
\hline \hline C & 4.221305 & 0.793982 & 5.316625 & 0.0000 \\
X1 & -0.347556 & 0.149337 & -2.327324 & 0.0269 \\
X2 & 0.333015 & 0.147511 & 2.257562 & 0.0314 \\
X3 & -0.251914 & 0.121236 & -2.077883 & 0.0464 \\
\hline \hline
\end{tabular}

Sumber: Data diolah, 2019

\section{Koefisien determinasi $\left(R^{2}\right)$}

Pengaruh variabel independen (Sadar Wisata, Kemenarikan Fasilitas Dan Jarak) terhadap variabel dependen (Minat Berkunjung Kembali) ditunjukkan oleh besar koefisien determinasi adjusted R-squared 0.379508 atau 37\% sehingga dapat dinyatakan memiliki korelasi keeratan kuat terhadap minat berkunjung kembali. Hal ini menjelaskan bahwa pengaruh sadar wisata (X1) kemenarikan fasilitas (X2) dan jarak (X3) sebesar 37\% dan sebesar 53\% dipengaruhi oleh variabel lain selain dalam model.

\section{Implikasi kebijakan}

Pemerintah kabupaten merangin harus meningkatkan realisasi investasi dibidang pariwisata setiap tahunnnya baik asing maupun domestik. Kemudian menarik investor ke daerah yang sangat membutuhkan kontribusi dari investor, baik asing maupun domestik sehingga investasi lebih merata dan dapat dirasakan oleh masyarakat kabupaten merangin dan berdampak meningkatnya minat berkunjung kembali wisatawan di kabupatenn merangin.Pemerintah kabupaten merangin seharusnya dapat meningkatkan belanja langsung dengan memperkecil anggaran untuk belanja tidak langsung, kemudian penambahan belanja langsung tersebut dapat menyentuh ke masyarakat walaupun secara tidak langsung dengan tujuan utama yaitu program yang berkaitan terhadap pembangunan infrastuktur yang dapat meningkatkan minat berkunjung kembali wisatawan di kabupaten merangin.

Kebijakan pihak pengelola akan selalu membuat inovasi dan penambahan sarana dan prasara guna menarik minat berkunjung kembali pada objek wisata merangin garden seperti pembangunan kebun buah-buahan, pembuatan kolam ikan, area bermain anak dan fasilitas pendukung lainnya.

\section{KESIMPULAN DAN SARAN Kesimpulan}

Berdasarkan kondisi sosial ekonomi para wisatawan dari 35 responden, diketahui rata-rata umur wisatawan merangin garden adalah 39 tahun. Rata-rata jenis kelamin wisatawan merangin garden adalah laki-laki. Rata-rata pendidikan adalah SMA/Sederajat. Rata-rata jumlah tanggungan (anak) wisatawan merangin garden adalah 3 orang. Rata-rata tempat tinggal wisatawan merangin garden adalah masyarakat merangin sebanyak 28 responden dan 7 responden berasal dari daerah diluar kabupaten merangin.Berdasarkan hasil analisis linear berganda dengan pendekatan OLS untuk melihat pengaruh sadar wisata, kemenarikan fasilitas dan jarak terhadap minat berkunjung kembali, maka diperoleh hasil dengan uji simultan dan bersama-sama bahwa variabel sadar wisata, kemenarikan fasilitas dan jarak berpengaruh positif dan signifikan terhadap minat berkunjung kembali pada objek wisata merangin garden. 


\section{Saran}

Dari hasil penelitian dapat disarankan khususnya kepada pengelola objek wisata merangin garden dengan input teknologi yang ada, karena dengan adanya teknologi dan akses internet dapat meningkatkan jumlah wisatawan baik itu di kabupaten merangin dan daerah lain nya lebih luas lagi.Upaya yang harus dilakukan oleh pengelola agar lebih melibatkan masyarakat sekitar kelurahan pematang kandis untuk bekerja sama dalam meningkatkan pelayanan dan fasilitas agar para wisatawan ingin mengunjungi kembali objek wisata merangin garden Peran pemerintah yang dapat dilakukan untuk meningkatkan jumlah wisatawan merangin garden adalah dengan cara mempromosikan objek wisata ini dan memberikan pelatihan/pendampingan kepada pihak pengelola dan karyawan untuk bisa merawat serta menambah fasilitas objek wisata merangin garden ini lebih baik lagi.

\section{DAFTAR PUSTAKA}

Ahmadi, (2019). Data pariwisata kabupaten merangin, wawancara 12 oktober 2019 pukul 09.00 WIB.

Amir, Dkk. (2009). Metodologi Penelitian, Lembaga FEB Universitas Jambi: Jambi.

Baum, Warren C, (2005). Investasi dalam Pembangunan Pariwisata di Indonesia, Universitas Indonesia: Jakarta.

Erawan, I Nyoman, (2014). Daya Tarik Wisata Di Indonesia, PT. Upada Sastra: Denpasar.

Ghozali, Dkk. (2011). Aplikasi Analisis Multivarriate dengan Program Spss 21 Update Pls Regresi. Cetakan Vll Badan Universitas Diponogoro: Semarang.

Gujarati Damonar, (2016). Ekonomitrika Dasar, PT. Erlangga: Jakarta.

Hasan Dkk, (2002). Uji Asumsi Klasik Dalam Pariwisata, Lembaga FEB Universitas Indonesia: Jakarta.

Joni, Iwan, 2019. Manager Merangin Garden, Kelurahan Pematang Kandis, Kabupaten Merangin.

Mill, (2010). Faktor Penting Dalam Meningkatkan Kunjunngan Wisatawan, Universitas Indonesia.

Pendit, (2002). Pariwisata Indonesia. PT. Raja Grafindo: Jakarta.

Spilane, James, (1987). Ekonomi Pariwisata, Kanisius: Jakarta.

Suparmoko, (2002). Surplus Konsumen Pariwisata Di Indonesia, Universitas Gajah Mada: Yogyakarta

Sugiono, (2002). Pengantar Ekonomi Mikro, PT. Raja Grafindo Persada: Jakarta.

Hang, Gie, (2006). Ekonomi Pariwisata, PT. Upada Sastra: Jakarta.

Undang-Undang Republik Indonesia Nomor 10 Tahun 2009 Tentang Kepariwisataan.

Undang-Undang Repuplik Indonesia Nomor 54 Tahun 1999 Tentang Pembentukan Kabupaten Merangin.

Undang-Undang Ketenagakerjaan Nomor 13 Tahun 2003.

Yoeti, Oka A, (2016). Pemasaran Pariwisata, PT.Angkasa: Bandung.

Yoeti, Oka A, (1990). Tours And Travel Management. PT.Pradnya Paramita: Jakarta.

Wahab, Abdul, (2017). Ekonomi Pariwisata. PT. Raja Grafindo: Jakarta.

Wiyono, (2015). Mikroekonomi. PT. Erlangga: Jakarta.

Wahyudi, Setyo, (2016). Konsep Dan Penerapan Ekonomitrika Mengunakan E-Views, PT.Rajagrafindo Persada: Jakarta.

Zaenuri Dkk, (2012). Fasilitas Pariwisata Di Indonesia, PT.Erlangga: Jakarta. 